\title{
A Ética como Problema Histórico
}

\section{From work to ethics: elements of a materialistic ontology.}

\author{
Ranieri Carli \\ Henrique André Ramos Wellen
}

Artigo

Original

Original

Paper

\begin{abstract}
Palavras-chaves:
Resumo

Ontologia

Trabalho

Ética

Este ensaio foi dividido em três momentos distintos: inicialmente, em trabalho e ser social, elucida-se a peculiaridade do ser social em face da natureza; em teoria do reflexo e valoração, demonstra-se com se dá o conhecimento das determinações da realidade; e, finalmente, em exteriorização e estranhamento, ilustra-se o duplo caminho posto ao ser social com a sua mediação com a natureza: o primeiro que possibilita a realização humana e a aproximação entre indivíduo e gênero, e o segundo que, por meio de barreiras socialmente construídas, o leva a processos de alienação.
\end{abstract}

\begin{abstract}
This assay was divided in three distinct moments: initially, in work and social being, it is elucidated the social being peculiarity in face of the nature; in theory of the consequence and valuation, it is demonstrated how it gives the knowledge of the reality determinations; and, finally, in exteriorization and aleination, it is illustrated the double way given to the social being in its mediation with the nature: the first one that makes possible the accomplishment human being and the approach between individual and sort, and the second that means the barriers socially constructed, that takes it to alienation processes.
\end{abstract}

\section{Trabalho e Ser Social}

O homem se diferencia dos animais pela sua capacidade exclusiva de projetar mentalmente aquilo que produz. Antecipar idealmente a realização futura chama-se teleologia. Como fala Marx em O Capital, a teleologia faz mesmo do pior dos arquitetos um ser qualitativamente superior a uma abelha. Isso se dá porque, diferentemente da abelha, o arquiteto, antes de começar a colocar no papel sua construção, já a detém na sua mente.

\section{Está escrito nos Manuscritos de Paris:}

$O$ animal identifica-se imediatamente com a sua atividade vital. Não se distingue dela. É a sua própria atividade. Mas o homem faz da sua atividade vital objeto da vontade
Key words:

Ontology

Work

Ethics

e da consciência. Possui uma atividade vital consciente. Ela não é uma determinação com a qual ele imediatamente coincide. A atividade vital consciente distingue o homem da atividade vital dos animais (Marx, 1993: 164, 165)

O trabalho não é, portanto, uma ação meramente instintiva de adaptação ao ambiente exterior. Somente os homens são capazes de ter e exercer um processo de transformação da natureza, de romper com os seus ditames biológicos ou naturais. Enquanto os animais utilizam-se da natureza para poder saciar as suas necessidades instintivas (como alimentação, moradia ou reprodução), o homem consegue ir muito além dessa limitação. Consegue, a partir da natureza, criar objetos que servem não apenas para as 
suas necessidades biológicas, mas também para fins culturais. Tudo isso é resultado da antecipação teleológica do produto do trabalho na consciência do homem.

\section{Na Estética, Lukács expõe a dialética ao falar do ritmo que nasce do trabalho:}

No trabalho, o homem toma alguma coisa da natureza, o objeto do trabalho, e arranca-o de sua conexão natural, submete-o a um tratamento pelo qual as leis naturais são aproveitadas teleologicamente em uma posição humana de fins. Isso se intensifica ainda quando aparece na ferramenta uma 'natureza' teleologicamente transformada desse modo. Assim se origina um processo, submetido sem dúvida às leis da natureza, mas que, como tal processo, não pertence já à natureza, e no que todas as interações são naturais só no sentido que parte do objeto do trabalho, porém sociais no sentido que parte da ferramenta, do processo de trabalho. Este caráter ontológico impõe um selo ao ritmo que assim se origina. Enquanto que no animal se trata simplesmente de que a adaptação fisiológica ao ambiente pode em determinadas circunstâncias produzir algo rítmico, no trabalho o ritmo nasce do intercâmbio da sociedade com a natureza (1982, I: 268).

Surge aqui uma dupla dialética na interação do homem com a natureza por meio da experiência privilegiada do trabalho, a saber: se por um lado, o homem transforma a natureza naquilo que deseja construir e com isso ocorre uma mudança quantitativa no seu objeto de intervenção, (concedendo o homem novas formas de uso para os materiais naturais), por outro lado, ocorre uma própria transformação nas habilidades e capacidades do ser humano. O homem que, ao transformar a natureza, transforma-se a si mesmo. Como estudou Engels (s/d), a mão humana não é só a mediação privilegiada do trabalho, mas também o seu produto.

Em síntese, o processo de mediação entre homem e natureza gera um duplo processo de transformação, tanto no objeto transformado (a natureza), como no sujeito da transformação (o homem). A natureza muda materialmente, sendo transformada em uma nova objetividade, agora social. Na Pequena ontologia, Lukács observa o que está implícito na presente discussão: o trabalho humano cria uma objetividade nova, "que não se apresenta na natureza" (1990: 18). Que se pense na roda, diria o filósofo húngaro nesse texto.

O objeto criado resulta como uma unidade homogênea entre dois polos: aquilo que é natural - a causalidade dada; e aquilo que é parte exclusiva do homem - a teleologia. Não é totalmente social (no sentido humano), nem é exclusivamente natural. Sua transformação de natural em social ocorre pela intervenção humana através do trabalho que, ao mesmo tempo em que imprime sua vontade sobre a natureza, também é por ela limitada e condicionada.

Somente o ato do trabalho pode concretizar a possibilidade almejada pelo pensamento, instaurando não apenas uma nova realidade pensada (ainda enquanto possibilidade de vir a ser), mas, efetivamente, numa nova realidade material-a transformação da causalidade dada em causalidade posta. É o processo que caminha da causalidade dada pela natureza à causalidade posta pelo homem. Por isso que o trabalho é a categoria modelar da práxis humana, aquela pode unir dois polos dialéticos: a causalidade e a teleologia, fundando a causalidade posta.

ara que fosse possível conservar uma unidade entre os dois contrários, não seria possível que ocorresse uma ruptura total (a transformação não pode ser tida como idêntica com ruptura, uma vez que permanecem, mesmo com outros arranjos, elementos e qualidades anteriores), uma negação da natureza e o surgimento de uma entidade completamente nova. Por certo, isso seria uma total abstração da dialética própria da natureza. Não se criam condições de desenvolvimento no vácuo das possibilidades. O homem é herdeiro genético da natureza; é seu filtro e aprendiz. Por outro lado, também é tão capaz de desenvolver-se que não apenas superou sua herança genética (conservando-a), mas, na mesma medida, forjou novas condições de desenvolvimento, ainda que condicionado e limitado pelas circunstâncias. Diante da matéria dada, o homem inventou, criou e utilizou formas de uso totalmente inéditas que não só possibilitou um grau superior nas condições existentes, assim como proporcionou um salto de qualidade. Basta o exemplo da roda, um objeto que não existe na natureza, para confirmar as assertivas anteriores. 
Esse processo de construção e transformação da natureza leva gradativamente a um distanciamento cada vez maior do homem das suas necessidades imediatas. O homem não só começa a transformar a natureza, mas, por meio do desenvolvimento de suas capacidades de intervenção advindas do duplo processo de mediação com a natureza, também começa a deter um certo controle sobre esta. Com a criação de equipamentos e técnicas, com o avanço da ciência e a subtração de terreno ao desconhecido, o homem humaniza-se cada vez mais e, com isso, passa a abandonar a sua condição meramente natural; é aquilo que Marx chamou de "recuo das barreiras naturais" em face do avanço dos limites sociais (cf. Marx, 1978).

O retraimento das barreiras naturais implica uma maior apropriação da natureza por parte do homem. Vejamos. Graças ao seu aspecto teleológico, o trabalho significa, desde o primeiro instante, um controle do objeto transformado. Assim, para se fazer efetiva a teleologia, é preciso intercambiar-se com a realidade sabendo como transformá-la. Para tanto há de se intuir como a dialética da natureza funciona em seus aspectos gerais; há de se tentar apreender as características da realidade natural.

\section{Teoria do reflexo e valoração}

Como o conhecimento amplo da realidade proporciona condições mais seguras para a sua intervenção, o ser social busca justamente diminuir essa distância entre o que é real e a sua imagem sobre o real. O homem busca representar mentalmente o movimento do real com a maior justeza possível, abarcando sempre elementos novos.

A apreensão do real trabalhado pode ser explicada assim com um exemplo de Markus:

Em sua atividade, o operário de um alto-forno estabelece uma relação determinada entre os seus vários sentidos particularmente exercitados. Dado que, para ele, são a cor e a luminosidade do ferro que indicam os estados físicos do objeto, os quais outrossim desempenham um decisivo papel em seu trabalho, o limite da diferença entre as diversas cores (que parece ser um dado puramente fisiológico) diminui de importância com relação ao seu critério de avaliação do múltiplo. Ou seja: o operário pode desenvolve faculdades óticas de que a maioria dos homens não dispõe, criando assim um mundo visual mais rico do que o normal, sem com isso ser obrigado a conhecer as propriedades singulares e os estados fisicos especificos. As propriedades dos objetos apresentam-se imediatamente como signos determinados das várias fases de sua atividade. O operário não necessita conhecer a essência dos processos fisico-químicos que se desenvolvem diante de seus olhos e dos quais ele se serve (1974: 72).

Esse conhecimento, cada vez mais apropriado, implica determinações novas na dialética que surge entre o homem e a objetividade natural. Na busca dos meios apropriados para a realização do seu trabalho, o homem guia as suas escolhas de acordo com a posição dos fins, com a finalidade projetada; aqui está a ponte entre o começo e o fim do processo do trabalho: a busca apropriada dos meios de execução do trabalho, úteis ao trabalho, a partir do justo conhecimento da realidade natural dada.

Por isso que, na direção encaminhada, se torna equivocada a equiparação entre instrumentalidade e utilidade, uma vez que a própria utilidade é aqui entendida como a base, a partir da captura do real, das possibilidades de concretização da teleologia ou, antes, do projeto idealizado. Nesse sentido preciso, o critério de instrumentalidade, como uma base racionalista fundada no cálculo, perde seu sentido pleno de negatividade, pois passa a ser inerente e determinante em qualquer ação. Essa distinção é precisamente a distância que há entre Weber e Lukács; enquanto o sociólogo alemão situa a racionalidade instrumental num momento seguinte da teleologia (poder-se-ia sugerir que apenas na finalidade), suspendendo-a da concretude do real, Lukács resgata, sem ser mecanicista ou determinista, a importância das determinações do real concreto (ou da vida cotidiana, como dizia o filósofo marxista) para a escolha humana, inter-relacionando-as dialeticamente (cf. Netto, 2000).

Para o pensador húngaro, o critério da utilidade é central para a decisão, tendo em vista que, só assim é possível concernir 
acerca das possibilidades concretas para a efetivação da vontade humana, enquanto Weber, conforme explicitado, negando as causalidades históricas, faz suspender a racionalidade da realidade concreta, negando o caráter determinante do real para a posição dos fins projetados. Entre os interstícios que sua teoria promove, Weber não só provoca uma diminuição da possibilidade efetiva da realização do pôr-teleológico como, de forma ainda mais grave, retira de pauta a real possibilidade da formação de uma consciência para si, pois, mesmo com a vontade concretizada, o ser social não terá consciência de suas limitações e possibilidades, do humano genérico de seu tempo particular, podendo crer que tudo o que conseguiu foi fruto exclusivo de sua valorização.

Não se deve perder de vista que o humano genérico de cada particularidade histórica condiciona os limites das ações individuais. Diante de cada contexto social, e da relação entre a totalidade e o indivíduo, da sociabilidade e da individuação, existe uma tensão viva que aponta para o que venha a ser predominante, ora o reflexo, ora o dever-ser. Se ancorado pela totalidade, na inter-relação entre teleologia e causalidade posta, e as suas respectivas formas de transformação em uma nova causalidade posta (que, dentro da teleologia é um ato secundário), o que se torna predominante é a captura em maior ou menor grau de determinação do real - o reflexo para melhor compreender quais os meios para pôr em prática o desejo. Por outro lado, tomando como foco o indivíduo (o processo de individuação), o que vai ser predominante para a sua ação é o projeto a ser realizado, é aquilo que se anseia a tornar-se real, o deverser está aí predominante na posição do fim.

Dessa maneira, ocorre uma imbricação entre as duas instâncias, quando entra em contato o individual com o universal, quando a escolha individual aproxima-se do genérico. Para alcançar o que se deseja é preciso refletir as mediações que se põem objetivamente na totalidade social. E o que motivará a ação, inclusive a busca pela sua concretização, será a posição do fim, o dever ser, sendo, até responsável pela aceitação ou rejeição do objeto construído. Temos, então, a realização condicionando o projeto e o projeto sendo a gênese da realização.

Apesar da posição dos fins ser o momento orientador da ação, este não pode efetivar-se sem a sua possibilidade concreta de realização, sem a existência de meios que concorram para a sua concretização. Nenhum projeto é pura abstração feita num vácuo de relações; a projeção ideal está sempre interligada com a realidade vigente, por mais estranha que possa ser vista. $\mathrm{O}$ pensamento só pode brotar de um campo que seja fértil. Metaforicamente, se poderia afirmar que não se podem colher frutos de uma árvore que não foi plantada ou que sequer exista a sua semente.

Dessa forma, estando o ser social imerso em sua sociabilidade determinada, sendo uma síntese das múltiplas determinações existentes em determinado período histórico, a finalidade representa uma interdependência com os valores. Esse seria, de forma extremamente simplificada, o poder da ideologia, que guia os atos humanos, conduzindo-os de acordo com o ordenamento social posto ou em oposição a ele, para que esses atos se insiram numa circularidade que legitime e naturalize a forma de organização existente, ou em uma tensão que rompa com as circunstâncias postas.

Essa contradição é peculiar das sociedades cindidas em classe. Os valores fazem parte da causalidade posta e interferem diretamente na escolha e na própria suscitação de possibilidades e alternativas a serem colocadas em prática; fazem parte dos elementos imanentes à particularidade histórica dada e seguem a intenção de manter a reprodução social. Por outro lado, valores também podem induzir às escolhas que possibilitem a transformação de causalidade posta em novas causalidades postas. Assim, valores presentes na ordem estabelecida podem servir para criar mesmo dentro das determinações instaurado um novo sistema valorativo a partir de um conjunto de novas causalidades postas.

Com isso, quer se dizer que a valorização pode resultar em mera reprodução da realidade dada, ou em transformação da individualidade em face das alternativas concretas. Abrem-se dois caminhos distintos para o ser social: uma tendência ao crescimento humano universal, por meio do acúmulo e socialização de experiências, ou o seu contrário, um retrocesso no sentido da humanização, ao forjarem-se barreiras sociais que se interponham entre o indivíduo e o 
gênero. O primeiro caso rumo ao progresso humano e o segundo levando a uma alienação entre os homens.

\section{Exteriorização e alienação}

O confronto do indivíduo com o produto de seu trabalho pode resultar em falência das intenções antes projetadas ou em sua realização; o indivíduo pode ter frustrado sua projeção inicial ou tê-la efetivado satisfatoriamente. Quando se realizam as intenções, há um reconhecimento entre o fruto do trabalho e o homem que o produziu. Esse processo de retorno do objeto ao indivíduo é o que Lukács chama de exteriorização: que o objeto retroage em seu criador. É assim que se compreende a tendência em que o indivíduo caminha rumo ao progresso humano, próximo ao humano genérico de seu tempo presente.

O seu oposto é o estranhamento: quando a conciliação do homem com o produto de seu labor é obstada por elementos exteriores. O objeto aparece como tendo uma vida própria. Parece uma coisa que, por ter independência, teria a capacidade de enfrentálo como um objeto estranho. Ao invés de servir para o crescimento humano, o objeto é visto como externo a seu próprio criador; na alienação não existem laços factuais aparentes que liguem o ser social ao objeto por ele construído e, com isso, o homem não se sente como fonte de sua produção, como o gestor dos objetos transformados.

\section{Lukács determina o caráter da objetivação especificamente alienada:}

A objetivação é, de fato, um modo de exteriorização insuperável na vida social dos homens. Quando se considera que na práxis tudo é objetivação, principalmente o trabalho, que toda forma humana de expressão, inclusive a linguagem, objetiva os pensamentos $e$ sentimentos humanos, então torna-se evidente que lidamos aqui com uma forma universal de intercâmbio dos homens entre si. Enquanto tal, a objetivação não é, por certo, nem boa nem má: o correto é uma objetivação, tanto quanto o incorreto; a liberdade, tanto quanto a escravidão. Somente quando as formas objetivadas assumem tais funções na sociedade, que colocam a essência do homem em oposição ao seu ser, subjugam, deturpam e desfiguram a essência humana pelo ser social, surgem a relação objetivamente social da alienação e, como consequência necessária, todos os sinais subjetivos de alienação interna (2003: 37).

Sendo a alienação uma barreira determinada socialmente que impede o ser humano de defrontar-se com seu caminho (práxis) através de sua particularidade e generalidade, podem-se inferir duas características centrais: a) que a alienação está em interna conectividade com a objetivação e, desta forma, com a esfera do trabalho; por meio do trabalho, de sua crescente complexificação, surgem, historicamente determinadas, essas barreiras sociais; b) por outro lado, apesar do trabalho ser a sua protoforma modelar, a alienação não se estabelece em seu domínio exclusivo; estando existente a partir de sua complexificação social, existe nas demais esferas da reprodução social.

A colisão entre as duas categorias (exteriorização e alienação) possui um vínculo crucial com a ética. O crescimento ético do indivíduo diz respeito ao reconhecimento de si como gênero humano; daí a necessidade histórica da ruptura com as alienações para o processo de individuação e sociabilidade.

$\mathrm{O}$ valor ético tem a sua fundação no trabalho, a partir das alternativas geradas pela interface entre homem e natureza. No entanto, o trabalho é fonte do valor, mas não garante suas características determinantes. $\mathrm{O}$ primado do valor no trabalho não permite a transposição direta das escolhas econômicas para as éticas. Aqui, os valores éticos obtêm um estreito laço com a questão do binômio exteriorização e alienação. Os valores podem servir tanto como mantenedores da ordem estabelecida como também podem servir para estimular a criação de coisas novas, assim como fortalecer para a condução humana na transformação social - configurados a partir do sentido criador e superador, presente na teleologia.

Colocando-se os valores como teleologia, que cria algo novo e não apenas reproduz o velho, então, as escolhas éticas passam a ser privilegiadamente voltadas para a transformação. Sendo teleologia assim adotada produtora da transformação, tudo o que a integra também se direciona para o novo, para o futuro. Por isso, o caminho do ser social para o progresso da humanidade, como 
tendencialmente genérico-humanizado.

Os valores podem servir para levar o ser social a dois caminhos distintos: à construção de uma sociedade mais próxima do desenvolvimento do gênero humano, ou uma sociedade que esteja cada vez mais longe do gênero humano. Na primeira forma, as escolhas fazem com que o homem sintase partícipe do seu futuro e do futuro de sua própria sociedade, enquanto que no segundo caso existe um distanciamento entre o singular e o universal, na medida em que se promove um isolamento do ser social que, ao restringirse a si mesmo (de forma instrumental) não se sente partícipe do devir social, nem do contato transformador com a natureza com os outros homens (cf. Lessa, 2002).

É somente com essa base que se pode tratar da ética, uma vez que, enquanto os outros complexos sociais relacionados à ideologia, como os costumes e a moral, estruturam-se a partir de regras sociais de cunho coletivista, mesmo transformados historicamente, a ética alcança o interlúdio entre o social (o coletivo não só visto como concreto, mas também como potencial) e o individual, possibilitando ao ser social sua objetivação plena. É essa diferença que se faz quando é preciso frisar que a existência da ética e as limitações impostas socialmente conduzem o ser social a processos de estranhamento: uma tendência decrescente da generalidade humana, na qual o particular desaparece no coletivo.

Porém, Markus explica que "a alienação é uma fase não só necessária, senão positiva, criadora — ainda que em forma contraditória — do desenvolvimento do ser do homem". Isso porque a dissolução das antigas comunidades e o avanço da sociabilidade mundialmente integrado "não [foram possíveis] senão por meio do período histórico e dos mecanismos da alienação" (1974: 64), por meio do processo de expansão do capital (a "missão histórica" da burguesia da qual falava Marx).

Desse modo, afirma Lukács, como última sociedade baseada na exploração, como a sociedade que produz não apenas as condições prévias econômicas materiais do socialismo, senão que traz à luz seus próprios coveiros, a sociedade capitalista tem que produzir, no seio das forças que deformam e desfiguram o homem, também aquelas forças progressistas que se orientam ao futuro (cf.
1982, 1: 68). Em meio às suas alienações, o movimento do capital intrinsecamente engendra a possibilidade da objetivação de sua superação e da emancipação universal da humanidade.

\section{Bibliografia}

ENGELS, Friedrich. Sobre o papel do trabalho na transformação de macaco em homem. In: MARX, Karl; ENGELS, Friedrich. Obras escolhidas. Vol. 2, São Paulo: Alfa-Omega, $\mathrm{s} / \mathrm{d}$.

LESSA, Sérgio. Mundo dos Homens: trabalho e ser social. São Paulo: Boitempo, 2002.

LUKÁCS, Georg. Prolegomini all'ontologia dell'essere sociale. Milano: Guerini \& associati, 1990.

- História e consciência de classe. São Paulo: Martins Fontes, 2003.

MARX, Karl. O Capital: crítica da economia política, liv. I, vol. II (o processo de produção capitalista). Rio de Janeiro: Civilização Brasileira, 1978.

- Para a crítica da economia política; salário preço e lucro; o rendimento e suas fontes. 2 ed. São Paulo: Abril Cultural, 1982. (col. Os economistas).

Manuscritos econômico-filosóficos.

Lisboa: Edições 70, 1993.

NETTO, José Paulo. Para a crítica da vida cotidiana. In: NETTO, José Paulo; CARVALHO, Maria do Carmo Brant de. Cotidiano: conhecimento e crítica. São Paulo: Cortez, 2000.

Endereço para Correspondência:

Prof $^{\circ}$ Ranieri Carli

Curso de Serviço Social

Email: ranieri.oliveira@foa.edu.br

Prof ${ }^{\circ}$ Henrique André Ramos Wellen

Curso de Serviço Social

Email: harw@uol.com.br

Centro Universitário de Volta Redonda

Campus Três Poços

Av. Paulo Erlei Alves Abrantes, nº 1325 ,

Três Poços - Volta Redonda / RJ

CEP: $27240-560$ 